\title{
A DINÂMICA POPULACIONAL DOS PAISES DESENVOLVIDOS E SUBDESENVOLVIDOS
}

João YUNES (1)

\begin{abstract}
YUNES, J. - A dinâmica populacional dos países desenvolvidos e subdesen-
\end{abstract} volvidos. Rev. Sauide públ., S. Paulo, 5:129-50, 1971.

RESUMo - Analisam-se os principais fatôres que contribuiram para a dinâmica populacional dos paises desenvolvidos e subdesenvolvidos, a política por êles adotada, bem como a aplicação da demografia em saúde pública. O ritmo de maior crescimento populacional observa-se nos países subdesenvolvidos sendo que, para o ano 2.000 , a região denominada de terceiro mundo é a que apresentará o maior contingente populacional pois os países subdesenvolvidos contribuirão com $79 \%$ do total da população mundial. A primeira transição demográfica iniciou-se no século 17, na Europa, com o processo de revolução industrial enquanto que, nos países subdesenvolvidos, isto ocorreu a partir do ano de 1940, porém, com uma diferença fundamental, pois a queda de mortalidade verificada não foi acompanhada por um declínio significativo da natalidade nem da modernização de suas economias. Entre os principais fatôres que afetam a mortalidade e a fertilidade analisou-se a influência do desenvolvimento econômico e social e dos avanços no campo da medicina e da saúde pública. Está sob uma política antinatalista oficial $66 \%$ da população dos países subdesenvolvidos e os contraceptivos mais utilizados têm sido, em ordem decrescente, o dispositivo intrauterino, esterilização e pílulas. Sòmente a India, em 4 anos (1964-68), esterilizou 5.200.000 habitantes com uma idade média de 32,2 anos. Entre as principais aplicaçóes da demografia em saúde pública destacam-se o planejamento de saúde, migrações, epidemiologia e higiene materno-infantil.

UnItermos - Dinâmica populacional *; Demografia*; Política populacional *; Saúde pública.

\section{INTRODUCAO}

0 crescimento populacional é, no mundo hodierno, sem dúvida, um dos temas mais debatidos $e$ as conseqüêencias dêste aumento um dos mais controvertidos.

No momento em que importantes deci- sões, que envolvem a política populacional, são discutidas tanto em países desenvolvidos como subdesenvolvidos, o esfôrço deverá ser concentrado no estudo, análise e investigação de caráter científico que

Recebido para publicação em 11-3-1971.

(1) Do Centro de Estudos de Dinamica Populacional do Departamento de Epidemiologia da Faculdade de Saúde Pública da USP, Av. Dr. Arnaldo, 715, São Paulo, SP - Brasil. Da Disciplina de Pediatria Social da Faculdade de Medicina da USP, São Paulo, SP - Brasil. Apresentado no "Seminário sôbre o Ensino da Proteção à Saúde Materna-Infantil, em funçăo das Necessidades da Comunidade, Salvador, nov. 1970" e no "Curso Internacional sobre Problemas Prenatais, Brasilia, DF, nov. 1970". 
YUNES, J. - A dinâmica populacional dos países desenvolvidos e subdesenvolvidos. Rev. Saúde públ., S. Paulo, 5:129-50, 1971.

possam superar a natureza apriorística e o nível emocional que, freqüentemente, dominam a controvérsia. As teses prónatalistas e teses a favor do contrôle da natalidade se opõem, sem que se elaborem importantes distinções a respeito de fatôres como a densidade demográfica, os recursos naturais, as tendências das taxas de natalidade, o processo de urbanização, isto é, fatôres demográficos, econômicos, sociais e culturais que determinam a conveniência de opções políticas concretas, suscitando uma das mais agudas controvérsias de nossa época.

\subsection{Crescimento populacional}

O presente trabalho tem por objetivo, indicar a possibilidade de adoção de uma política populacional para os países subdesenvolvidos em geral e para o Brasil em particular. Para tanto, analisa-se o crescimento populacional e a transição demográfica ocorridos nos paises desenvolvidos e subdesenvolvidos, bem como os principais fatôres econômicos e sociais que afetaram a mortalidade e fertilidade. Considera-se a situação da política populacional nos países subdesenvolvidos e a dimensão que a demografia pode ter na aplicação em saúde pública.

A fonte de dados secundários mais utilizada foi a das Nações Unidas e, a seguir, apresenta-se os principais resultados desta análise.

Apesar da dificuldade de se obter dados estatísticos fidedígnos, o conhecimento geral do incremento populacional no passado apresenta-se bastante claro e a sua constatação serve de valioso marco de referência para a consideração do problema atual.

Durante a maior parte da história da humanidade, a população mundial aumentou a um rítmo lento, uma vez que tanto o coeficiente de natalidade quanto o coeficiente de mortalidade eram elevados. A mortalidade em massa, devido a epidemias freqüentes, inanição periódica e guerras, manteve baixo o crescimento populacional.

Para a população mundial duplicar-se a partir do comêço da Era Cristã foram necessários 1650 anos. 0 primeiro cálculo digno de confiança data dêste ano em que a população estimada era de 500 milhões de habitantes. Nos dois séculos seguintes esta cifra dobrou. Em menos de um século duplicou-se novamente $\mathrm{e}$ com as taxas atuais de crescimento, dobrará novamente em um têrço de século (Tabela 1) ${ }^{2}$.

TA B ELA 1

População estimada para o mundo e o número de anos requeridos para dobrar.

\begin{tabular}{c|c|c}
$\begin{array}{c}\text { Ano } \\
\text { (A.D.) }\end{array}$ & $\begin{array}{c}\text { População (em } \\
\text { milhōes) }\end{array}$ & $\begin{array}{c}\text { N.o de anos } \\
\text { requeridos para } \\
\text { dobrar }\end{array}$ \\
\hline I & 250 & 1650 \\
1650 & 500 & 200 \\
1850 & 1000 & 80 \\
1930 & 2000 & 45 \\
1975 & 4000 & 35 \\
\hline
\end{tabular}

Fonte: DORN (1965)2.

A rápida expansão populacional verificada na Tabela 1 , não foi devida a um crescimento homogêneo da população. 0 rítmo de maior crescimento se observa nos países considerados subdesenvolvidos, enquanto que as nações desenvolvidas permanecem pràticamente estacionárias, isto é, crescem em rítmo acentuadamente menor, conforme se verifica nas Tabelas 2 e $3^{7}$.

De acôrdo com os dados apresentados, as regiōes de maior contingente populacional por ordem decrescente são representadas pela Ásia, Europa, África, América Latina, União Soviética, América do Norte e Oceania. Para o ano $2.000 \mathrm{com}$ as taxas de crescimento previstas, ocorrerá uma alteração nesta ordem. As regiốes que apresentarão por ordem decres- 
YUNES, J. - A dinamica populacional dos paises desenvolvidos e subdesenvolvidos. Rev. Saúde públ., S. Paulo, s:129-50, 1971.

TABELA 2

Crescimento populacional

\begin{tabular}{|c|c|c|c|c|c|}
\hline \multirow{3}{*}{ Ano } & \multicolumn{5}{|c|}{ População (em milhões) * } \\
\hline & \multirow{2}{*}{$\begin{array}{l}\text { Paises } \\
\text { desen- } \\
\text { volvi- } \\
\text { dos ** }\end{array}$} & \multicolumn{4}{|c|}{ Paises subdesenvolvidos } \\
\hline & & Total & $\begin{array}{l}* \\
* \\
\frac{5}{5} \\
4 \\
4\end{array}$ & 总恋 & Africa \\
\hline 1900 & 554 & 996 & 813 & 63 & 120 \\
\hline 1925 & 700 & 1207 & 961 & 99 & 147 \\
\hline 1950 & 838 & 1659 & 1297 & 163 & 199 \\
\hline 1975 & 1115 & 2741 & 2107 & 303 & 331 \\
\hline 2000 & 1448 & 5459 & 4145 & 651 & 663 \\
\hline
\end{tabular}

Aumento percentual

\begin{tabular}{rrrrrr}
\hline $1900-1925$ & 26.4 & 21.2 & 18.2 & 57.1 & 22.5 \\
$1925-1950$ & 19.7 & 37.4 & 25.0 & 64.6 & 35.4 \\
$1950-1975$ & 33.0 & 65.2 & 62.5 & 85.9 & 66.3 \\
$1975-2000$ & 29.9 & 99.2 & 96.7 & 114.8 & 100.3 \\
\hline
\end{tabular}

Percentagem total do globo

\begin{tabular}{llllll}
\hline 1900 & 35.7 & 64.3 & 52.4 & 4.1 & 7.7 \\
1925 & 36.7 & 63.3 & 50.4 & 5.2 & 7.7 \\
1950 & 33.6 & 66.4 & 51.9 & 6.5 & 8.0 \\
1975 & 28.9 & $\mathbf{7 1 . 1}$ & 54.6 & $\mathbf{7 . 9}$ & 8.6 \\
2000 & 21.0 & $\mathbf{7 9 . 0}$ & 60.0 & 9.4 & 9.6 \\
\hline
\end{tabular}

(*) 1900-1950 enumerados ou estimados; 1975 e 2000 projetados.

(**) Inclui Europa, URSS, América do Norte, Autrália, Nova Zelândia e Japão.

(***) Exclui a porção Asiática da URSS e o Japão.

Fonte: (com modificações): United Nations. Department of Economic and Social Affairs apud DORN ${ }^{2}$.

TABELA 3

População mundial e por regiōes (em milhões)

\begin{tabular}{c|c|c|c|c|c|c|c|c}
\hline Ano & Mundo & Asia & Africa & $\begin{array}{c}\text { Amé- } \\
\text { rica do } \\
\text { Norte }\end{array}$ & $\begin{array}{c}\text { América } \\
\text { Latina }\end{array}$ & Europa & Oceania & URSS \\
\hline 1970 & 3.632 & 2.056 & 344 & 228 & 283 & 462 & 19 & 243 \\
\hline $\begin{array}{l}\text { Projeçóes para o ano 2.000 } \\
\text { Fertilidade constante- ONU }\end{array}$ & 7.522 & 4.513 & 860 & 388 & 756 & 571 & 33 & 402 \\
\hline $\begin{array}{l}\text { Projecões para o ano 2000, } \\
\text { Estimativa média - ONU }\end{array}$ & 6.130 & 3.458 & 768 & 354 & 638 & 527 & 32 & 353 \\
\hline
\end{tabular}

cente um tamanho populacional maior serão: Ásia, África e América Latina, seguindo-se os outros continentes. Portanto, para o ano 2.000 , a região denominada do terceiro mundo é a que apresentará o maior contingente populacional, pois os países subdesenvolvidos contribuirão com $79 \%$ do total da população, sendo $60 \%$ da Ásia, 9,6\% da África e 9,4\% da América Latina. Os paises desenvolvidos contribuirão com apenas $21 \%$ da população mundial.

Esta situação está preocupando muito mais os países desenvolvidos. Estaria aí a razão da política do contrôle populacional e do financiamento, por parte dêstes países, nos programas de contrôle da natalidade?

Esta problemática será discutida com maiores detalhes porém, é digno de nota ressaltar-se que o principal fator responsável pila queda de mortalidade nos países desenvolvidos ocorreu quando êstes ingressaram no processo de desenvolvimento industrial.

\subsection{Transição demográfica}

A diversidade na tendência da mortalidade e do comportamento reprodutivo entre os países desenvolvidos e subdesenvolvidos é explicável pela chamada transição demográfica.

No passado, o aumento populacional apresentou um padrão de crescimento, em geral, semelhante, com algumas varia-

Fonte: POPULATION REFERENCE BUREAU \$. 
YUNES, J. - A dinamica populacional dos paises desenvolvidos e subdesenvolvidos. Rev. Saúde públ., S. Paulo, 6:129-50, 1971.

ções locais. Foi na Europa, mais ou menos na metade do século 17 , que se manifestou a primeira transição demográfica e que se repetiu em outros países, à medida que êstes passavam por um processo de revolução industrial.

Os elevados coeficientes de natalidade e mortalidade, são características típicas das economias agrícolas pré industriais.

A medida que uma sociedade agrícola começa a transformar-se em uma estrutura econômica mais moderna, a mortalidade começa a diminuir. A medida que se desenvolve a economia, há uma maior oferta de trabalho, as cidades crescem e se urbanizam, os transportes são melhores e mais rápidos, eleva-se a produtividade e o ingresso per capita e, conseqüentemente, um melhor bem estar social. A revolução industrial produziu enorme progresso no conhecimento científico, contribuindo para o contrôle de muitas doenças endêmicas, permitindo, em alguns casos, eliminar certas enfermidades. Os países atualmente desenvolvidos passaram por esta etapa que lhes permitiu beneficiar-se dêste desenvolvimento, reduzindo sua mortalidade.

No padrão histórico típico, decresce, primeiro, a mortalidade enquanto que a natalidade se mantém alta por um certo tempo. Portanto, existe um período caracterizado por uma natalidade elevada e uma mortalidade declinante. $\mathrm{Na}$ atualidade, esta última sofreu tão rápida redução que levou alguns autores a denominarem o fenômeno de "explosão demográfica". Há dúvida quanto a existência da verdadeira "explosão demográfica". Com o tempo inicia-se uma nova etapa de transição demográfica. As pessoas começam a limitar deliberadamente o número de filhos trazendo, como conseqüência, a queda da natalidade. Este processo é o resultado de um grande número de decisóes pessoais e não de uma política oficial de contrôle populacional, mesmo porque, durante esta fase de transição demográfica, não havia contraceptivos mecânicos, químicos ou hormonais.
Não se sabe, exatamente, qual é o principal fator que determinou a queda, porém, se considera que a taxa decrescente de natalidade está associada ao processo de industrialização, urbanização, aumento do nivel educacional, participação da mulher na força do trabalho e do desaparecimento da atitude fatalista em relação ao nascimento e à morte infantil. Os países que já efetuaram a transição de uma economia agrícola, de baixos ingressos, para uma urbana e industrial, com ingressos mais altos, seguiram estas etapas. Portanto, no início, as taxas elevadas de natalidade e mortalidade compensam-se entre si e o resultado é um crescimento demográfico lento. Numa segun$\mathrm{da}$ fase começa a queda de mortalidade com manutenção da natalidade ainda em nivel alto, trazendo como conseqüência o acelerado aumento populacional. Numa terceira fase, a mortalidade e natalidade equilibram-se a um nivel muito mais baixo e o crescimento novamente é lento. Este processo denomina-se transição demográfica.

Os países altamente desenvolvidos já passaram por estas etapas. Em algumas áreas do mundo em que êste fenômeno ocorreu, está se processando uma nova mudança, em que a prosperidade econômica tem dado lugar a um incremento moderado de população, que se ignora por quanto tempo perdurará.

Por volta de 1940, as naçóes menos desenvolvidas iniciaram uma mudança demográfica. Um nôvo padrão começou a aparecer que, em certos aspectos, se assemelha à antiga transição demográfica mas, ao mesmo tempo, apresenta diferenças fundamentais porque ocorre em uma época muito diferentes da do séc. 17.

Existe, atualmente, possibilidade de reduzir-se o coeficiente de mortalidade sem modernização da economia agrícola. No passado, os conhecimentos médicos desenvolveram-se a um rítmo lento, concomitantemente ao de transformação econômica. Algumas das armas mais efetivas contra a enfermidade e a morte, tais co- 
YUNES, J. - A dinamica populacional dos paises desenvolvidos e subdesenvolvidos. Rev. Saride pribl., S. Paulo, s:129-50, 1971.

mo os quimioterápicos, antibióticos e vários inseticidas, são produtos mais recentes dos países industrializados, inclusive posteriores à queda das taxas de mortalidade e natalidade e o aparecimento do padrão de familia reduzida ${ }^{1}$.

Os países menos desenvolvidos têm podido aproveitar-se dos conhecimentos médicos e de saúde pública dos países desenvolvidos, reduzindo sua mortalidade, sem haver modernizado suas economias.

Muitos países subdesenvolvidos têm ainda índices de mortalidade e de esperança de vida ao nascer idênticos aos da Europa em 1915 e os níveis econômicos bem como o padrão geral de vida, aos de 1840 a 1850.

Uma das conseqüências demográficas da estagnação ou do pequeno progresso econômico e social nos países não industrializados é a manutenção de índices de natalidade elevados.

Portanto, o que caracteriza os países subdesenvolvidos, quanto a sua dinâmica populacional, é a queda brusca da mortalidade, ocorrida, sobretudo, após a segunda guerra mundial sem ser acompanhada no declínio da fertilidade que permanece com taxas elevadas.

\section{FATORES ECONOMICOS E SOCIAIS QUE AFETAM A MORTALIDADE}

Mudanças no padrão de mortalidade estão relacionadas com a mudança da estrutura social e econômica. Alguns dos mesmos fatôres sociais e econômicos que afetam a mortalidade também afetam a fertilidade e a migração.

\subsection{Fatôres que contribuiram para a alta mortalidade}

\subsubsection{Nos paises desenvolvidos}

Os registros mostram que a população européia teve um coeficiente de mortalidade tão alto quanto os agora observados na maioria dos países subdesenvolvidos.
Embora o conhecimento das condições de mortalidade, nos primeiros séculos, seja precária, é evidente que a duração de vida, neste tempo, foi curta. Uma tábua de vida, constituída a partir dos registros de óbito na Grécia, indica uma média, na esperança de vida, de 30 anos, no ano de, mais ou menos, 400A.C. Estimativas na esperança de vida, em vários países europeus, do séc. 13 ao 17 , baseadas em dados fragmentados, variaram de 20 para 40 anos. No séc. 18, 1755-1776, a esperança de vida ao nascer variou de 33 para 40 anos (Suécia 33,2 anos para o homem e 35,7 anos para a mulher; França 37,5 anos para ambos os sexos). Estes dados podem ser comparados com a esperança de vida ao nascer na Índia, durante os anos de 19211931, que foi de 27 anos. Estes níveis contrastam com a vida média européia que é, hoje, de 65 anos ou mais, em muitos países europeus.

As indicações do coeficiente de mortalidade entre os países europeus, durante o séc. 18, também evidencia a alta mortalidade. Nas duas primeiras décadas do séc. 19, a mortalidade, em tôda Europa, excedia a 32 óbitos por mil habitantes, cêrca de três vêzes, em média, maior que a atual.

As condições de mortalidade na Europa e Estados Unidos, há 150 a 200 anos atrás, são as mesmas que as apresentadas hoje na maioria dos países subdesenvolvidos.

As informações que serão apresentadas a seguir parecem sugerir que as condições de vida da sociedade européia, que foram responsáveis por uma alta mortalidade, não foram muito diferentes daquelas prevalentes hoje nos países subdesenvolvidos.

\subsubsection{Fome e escassez de alimentos}

$\mathrm{Na}$ metade do séc. 19 , as populações européias foram vítimas de inanição fre- 
YUNES, J. - A dinâmica populacional dos paises desenvolvidos e subdesenvolvidos. Rev. Saúde públ., S. Paulo, 5:129-50, 1971.

qüente. A falta de transporte fazia com que cada pequena localidade dependesse de sua própria colheita e uma falha desta, resultaria em inanição, mesmo que, em localidades relativamente perto, a colheita fosse normal. Durante o séc. 18 a França, o mais rico país do continente, sofreu repetidos períodos de inanição. Pelo menos 9 severas falhas da colheita foram registradas nos países escandinavos entre 1740 e 1800 , e, cada uma delas, resultando em um acentuado aumento do coeficiente de mortalidade. $\mathrm{Na}$ Noruega, o coeficiente de mortalidade, em 1741, foi três vêzes maior que em 17361740 , tendo morrido, no referido ano, 1/15 da população, tendo sido a principal causa, a falha de colheitas, que assolou todo o norte dos países europeus. $\mathrm{Na}$ Suécia, durante a severa inanição de 1773 , o coeficiente de mortalidade elevou-se para $52,5 / \mathrm{mil}$ habitantes ${ }^{8}$.

Todos os grupos etários parecem ser afetados pela escassez de alimentos. É na criança que o crescimento e o desenvolvimento é atrasado ou permanentemente retardado.

\subsubsection{Epidemias}

Até recentemente, a peste, cólera, varíola, tifo e outras enfermidades ocorreram freqüentemente na Europa, agravadas pela carência de alimentos, foram responsáveis por elevada mortalidade.

Gilson estimou que a peste, no ano 543 D.C., foi responsável pela morte de cem mil pessoas. Esta enfermidade extendeu-se por tôda a Europa e permaneceu por várias décadas. Sòmente em 1348, a peste matou cêrca de 25 milhões de habitantes, $1 / 4$ da população européia dessa época ${ }^{8}$.

Doenças, como varíola e febre tifóide, foram disseminadas durante todo o tempo. Quando as epidemias coincidiam com os anos de más colheitas, o aumento da mortalidade era bem maior.

A variola era responsável por grandes epidemias antes da introdução da vacina- ção. Em Londres, em 10 anos (16811690), a mortalidade por varíola foi de 3 óbitos por mil habitantes. Nos séculos 17 e 18, êste coeficiente, frequientemente, alcançava um índice de $4,5 / \mathrm{mil}$, sendo responsável por cêrca de $1 / 10$ de tôdas as mortes. A varíola foi, pràticamente, eliminada um século após a descoberta da vacina, sendo a última epidemia severa desencadeada no continente europeu, no período de 1870-1873.

O tifo é registrado como tendo assolado a Europa desde o séc. 17 até fins do séc. 19. As epidemias por tifo ocorriam em épocas próximas a guerras e períodos de inanição, responsabilizando-se por um enorme número de vítimas.

A tuberculose, embora não ocorresse sob a forma epidêmica, foi uma das principais causas de morte na população jovem (crianças e adolescentes).

Estudos das causas destas calamitosas epidemias, geralmente, indicam que elas foram devidas, em grande parte, ao precário saneamento do meio e higiene pessoal, os quais, por sua vez, estavam ìntimamente ligados à falta de conhecimentos médicos e os baixos padrões de condiçóes de vida.

\subsubsection{Condições das áreas urbanas}

$\mathrm{Na}$ Europa, antes do século 20, o coeficiente de mortalidade foi maior nas cidades do que em outras áreas. Süssmilch apud United Nations ${ }^{8}$ estimou que, em Brandeburgo (1739-1748), o coeficiente de mortalidade foi ao redor de $25 / \mathrm{mil}$ habitantes nas áreas rurais, $31 / \mathrm{mil}$ em cidades menores e $36 / \mathrm{mil}$ em grandes cidades como Berlim. Em Estocolmo, nos anos de 1775-1776, de acôrdo com Price apud United Nations ${ }^{8}$, a esperança de vida ao nascer era, sòmente, de cêrca de 14 anos para o homem e 18 anos para a mulher, enquanto que, para a Suécia como um todo, era de 33 e 36 anos respectivamente. Nos Estados Unidos, em 1830, as condições de mortalidade foram bem piores nas 
YUNES, J. - A dinâmica populacional dos países desenvolvidos e subdesenvolvidos. Rev. Saúde públ., S. Paulo, 5:129-50, 1971.

grandes cidades do que nas pequenas e nas áreas rurais. A maior mortalidade urbana do que a rural persistiu em alguns países até mesmo no fim do séc. 19. Nesta época, Weber apud United NATIONs ${ }^{8}$, reportou o excesso de mortalidade urbana, em relação à rural, nos EUA, Rússia, Inglaterra e Holanda. Êste autor associou a variação da mortalidade com o grau de aglomeração e atribuiu a maior mortalidade urbana a uma maior "negligência" e "indiferença" urbana ${ }^{8}$.

As condições da vida urbana na Europa e América, nos séculos 18 e 19, é suficiente para indicar algumas das razões da excessiva mortalidade urbana. As cidades, nesta época, encontravam-se congestas, insalubres, com muitos doentes e eram formadas por grandes aglomerados, habitações com precaríssimas condições de higiene que se agrupavam ao redor dos locais de trabalho. Dentro das indústrias havia precária ventilação, a temperatura era muitas vêzes bem elevada, a iluminação precária, as horas de trabalhos longas e exaustivas e o risco de acidentes era maior. As ruas eram estreitas, com precária rêde de abastecimento de água e esgôto e ausência de áreas para recreação. Tais condições predispunham a um aumento de mortalidade, principalmente da criança.

\subsubsection{Nos países subdesenvolvidos}

Tem sido assinalado em muitos estudos que a alta mortalidade é característica das regióes econômicamente subdesenvolvidas da África, Ásia e América Latina, estabelecendo relação com os baixos níveis de vida, educação e dificuldades de assistência médica.

Quando os dados, para mostrar a relação entre os coeficientes de mortalidade e certos índices de condições econômicas e sociais, são disponíveis, êles indicam que a alta mortalidade é associada à baixa renda per capita, elevado indice de analfabetismo, grande contingente de população rural e grande número de habitantes por médico.
Em áreas de alta mortalidade, as doenças transmissiveis foram responsáveis por uma grande parte dos óbitos. $\mathrm{Na}$ fndia, a cólera, varíola e a peste assumiram proporções consideráveis e a tuberculose é elevadamente prevalente. Pelo menos, estima-se que cem milhões de habitantes sofrem anualmente de malária e cêrca de 2 milhões morrem por ano, direta ou indiretamente, como conseqüência desta doença. Em muitos países, o coeficiente de mortalidade por diarréias e enterites é elevado, a febre tifóide e tifo são endêmicas e epidemias por varíola não são raras. Em Porto Rico, onde a mortalidade tem caído consideràvelmente em anos recentes, a diarréia e tuberculose participam com mais de $1 / 3$ do total do número de óbitos nos anos próximos de 1940.

$\mathrm{Na}$ maioria dos países africanos, as principais causas de morte incluem a doença do sono, malária, tuberculose, esquistossomose, ancilostomíase, lepra, doenças venéreas, varíola, pneumonia e desnutrição. 0 coeficiente de mortalidade geral foi estimado para o período de 19391946, na África do Sul entre 21 e 25/mil habitantes comparado com $9 / \mathrm{mil}$ para a população européia.

Os fatôres sociais e econômicos responsáveis pelo baixo nível de saúde são semelhantes em tôdas as áreas dos países subdesenvolvidos. $O$ saneamento do meio é precário; a deficiência nutricional é elevada, tornando a população mais susceptível às doenças; os serviços de saúde existentes são inadequados e uma grande parte da população tem baixo poder aquisitivo para manter sua saúde protegida.

Geralmente dentro dos países subdesenvolvidos de hoje, a má nutrição é crônica, as doenças infecciosas são endêmicas, as quais, periòdicamente tornam-se epidêmicas, contribuindo como causa mais imediata pelo excesso de mortalidade nestas áreas. Estas causas são sintomas de pobreza, estando envolvidos fatôres políticos, culturais, religiosos e geo-físicos. 
YUNES, J. - A dinâmica populacional dos paises desenvolvidos e subdesenvolvidos. Rev. Saúde públ., S. Paulo, 5:129-50, 1971.

2.2 Fatôres que contribuiram para a redução da mortalidade

\subsubsection{Nos paises desenvolvidos}

O comêço do séc. 19, especialmente a partir de 1850, constata-se o grande progresso que se começou a alcançar no combate a enfermidades e mortes e no prolongamento da vida humana. Estudos da redução da mortalidade que ocorreu nêste período $\mathrm{e}$ as mudanças econômicas e sociais que a acompanharam, mostram a maior evidência da relação entre mortalidade e fatôres econômicos e sociais.

A redução do coeficiente de mortalidade não foi uniforme para os diferentes grupos etários. Nos países europeus, a redução da mortalidade, a partir do séc. 20 , tem sido, geralmente, mais acentuada nos casos de crianças e adolescentes. $\mathrm{Pa}$ ra o grupo etário acima de 75 anos o decréscimo registrado tem sido discreto. $\mathrm{Na}$ Suécia, entre 1751-1800 e 1901-1945, a mortalidade para o grupo etário menor de 15 anos foi reduzida de 72 a $84 \%$. Esta redução para o grupo etário com mais de 65 anos, para o período de 19011945, foi de $32 \%$. Na Suécia, a redução ocorreu, primeiro, entre crianças menores de um ano, depois, para o grupo etário de 1 - 5 anos e, finalmente, para o grupo de 5-14 anos. Na Inglaterra, no entretanto, na segunda metade do séc. 19, a mortalidade foi maior para o grupo etário de 5-14 anos que para crianças menores de 5 anos.

\subsubsection{Influência do desenvolvimento econômico}

Indubitàvelmente, a redução acentuada da mortalidade na Europa, a partir do séc. 18 , tem sido devida, principalmente, à grande melhoria da situação econômica da população, através da industrialização, desenvolvimento comercial e agrícola e ao avanço, da medicina e saúde pública que se verificou nestes países. Outros fatôres contribuintes foram a mecanização da agricultura, inovações técnicas, disponibilidade de fertilizantes artificiais, meios de transporte e comunicaçōes. A inanição foi eliminada, habitações mais adequadas foram construidas, roupas melhores foram viáveis, houve um aumento da renda familiar. Todos êstes fatôres contribuiram para a melhoria da saúde da população.

\subsubsection{Influência das legislações so- ciais}

A elaboração de uma legislação sanitária e o estabelecimento de agências de saúde estatais, principalmente na Inglaterra e Estados Unidos, contribuíram para a redução da mortalidade. Outro fator importante foi o aumento da idade mínima para o trabalho da criança e da mulher e a melhoria do meio ambiente de trabalho. Isto se verificou para a Inglaterra, Alemanha e outros países europeus. $\mathrm{Na}$ França e Inglaterra, uma lei estabelecida em 1850 e 1851, respectivamente, autorizou a condenação das habitações insalubres.

\subsubsection{Influência do desenvolvimento do saneamento do meio}

Foi no séc. 19, também, que ocorreu uma grande expansão dos serviços públi$\cos \mathrm{e}$, entre êles, houve uma melhoria considerável do saneamento do meio. Estabelecimentos públicos para remoção dos dejetos começaram a operar, em Londres, em 1848 e, em 1865, se instalou a rêde de esgôto. A purificação do suprimento de água iniciou-se no comêço do séc. $19 \mathrm{com}$ a instalação de filtros de areia em Paris. Em Londres, contou-se com êste recurso em ampla escala a partir de 1829 mas foi sòmente ao redor de 1875 que o uso de filtro espalhou-se através da Europa. $\mathrm{O}$ tratamento de água através da cloração começou a ser praticado no início do séc. 20 . Nesta época, a maioria dos países do mundo ocidental e a Rússia já tinham introduzido sistemas de abastecimento de água e remoção dos dejetos, contribuindo para a melhoria das condições gerais de saúde. 
YUNES, J. - A dinâmica populacional dos paises desenvolvidos e subdesenvolvidos. Rev. Saúde puibl., S. Paulo, 5:129-50, 1971.

Como resultado da melhoria das condições de saneamento a mortalidade por tifo, cólera, peste e as doenças do aparelho digestivo declinaram consideràvelmente. Houve, também, um interêsse crescente na higiene pessoal. 0 uso do sabão, que até então era considerado luxo, tornou-se de uso mais comum no séc. 19.

\subsubsection{Influência do desenvolvimento das ciências e dos programas de saúde pública}

Antes do séc. 19, a redução da mortalidade foi resultado, primeiramente, da melhoria dos fatôres não médicos pois, era pouco conhecido, neste tempo, o papel que desempenhavam os organismos patogênicos na etiologia das enfermidades. Desde então, importantes descobertas no campo médico e de saúde pública têm sido associadas a mudanças bruscas na mortalidade. Por exemplo, a vacinação contra a variola foi uma medida simples e bastante eficaz para o contrôle da enfermidade considerada até então, talvez, de maior letalidade.

A mortalidade decorrente de doenças infecciosas e de epidemias foi reduzida substancialmente a partir do último século como resultado dos progressos sociais, econômicos e médicos. Incluídas nesta categoria encontram-se as doenças como: febre tifóide, escarlatina, coqueluche, malária, varíola e tifo.

A redução das doenças infecciosas foi responsável pela redução da mortalidade, principalmente, nas crianças e no grupo etário jovem. Estas doenças reduziramse de $87 \%$, na Inglaterra, entre os anos próximos de 1850 e o ano de 1947. Neste período, a diarréia e enterites, principal causa de morte na infância, foi reduzida de $86 \%$ e a pneumonia em $53 \%$. Nos Estados Unidos, no período de 19001946, o coeficiente de mortalidade por pneumonia foi reduzido em cêrca de $80 \%$ e de tuberculose acima de $80 \%$. A mortalidade por diarréia e enterites e por doenças transmissiveis da criança foi re- duzida em mais de 95\%. Na Checoslováquia em 1919, a mortalidade por tuberculose e doenças da infância decresceram marcadamente. Comparativamente, pouco avanço tem sido feito no contrôle às doenças degenerativas, as quais, primàriamente, afetam pessoas idosas.

\subsubsection{Nos paises subdesenvolvidos}

$\mathrm{Na}$ maioria dos países da América Latina, Ásia e África, uma longa série histórica de dados de mortalidade apresentam-se bastante precários e falhos. É evidente, no entretanto, que a mortalidade nestas regióes do mundo, quase que universalmente permaneceu muito alto até relativamente anos recentes.

Em relação às causas responsáveis pela queda da mortalidade nos países subdesenvolvidos, três importantes fatôres merecem ser mencionados:

a) Enquanto nos países europeus o declínio de mortalidade foi dependente do desenvolvimento econômico e científico, os países subdesenvolvidos beneficiaram-se da importação destas técnicas e conhecimentos.

b) Eossível alcançar a redução da mortalidade nos países subdesenvolvidos a um preço relativamente baixo. Como a mortalidade nestes países foi extremamente alta, uma grande redução foi possível com a aplicação de técnicas simples e relativamente baratas.

c) 0 declínio da mortalidade não pode ser sempre atribuído ao melhoramento das condições econômicas da população. A saúde pública e as técnicas médicas têm contribuído para a manutenção e o aumento da vida média do homem, sem um acompanhamento na melhoria das condições econômicas. Portanto, os países subdesenvolvidos têm podido aproveitar-se dos conhecimentos médicos e de saúde pública sem ter havido modernização de suas economias. 
YUNES, J. - A dinâmica populacional dos paises desenvolvidos e subdesenvolvidos. Rev. Sailde públ., S. Paulo, 5:129-50, 1971.

A rápida queda na redução da mortalidade pelo qual muitos países da América Latina, Ásia e África passaram durante as décadas mais recentes, é ilustrada através da queda da mortalidade geral que se verificou em 9 dêstes países (1) $\mathrm{em}$ que o seu coeficiente foi de $21 / \mathrm{mil} \mathrm{em}$ 1932; 15/mil em 1947 e 13,5/mil em 1949.

Durante a década de 1935-1944, a mortalidade no México por varíola decresceu de $35,4 \%$ e por difteria em $25,3 \%$. O uso de inseticidas (DDT) que desempenhou um importante papel na campanha antimalárica, também contribuiu, consideràvelmente, para a redução da mortalidade por várias outras doenças transmissíveis veiculadas por insetos (febre amarela, doença do sono, tifo exantemático). Em Porto Rico, a mortalidade por malária decresceu de 125/cem mil habitantes, em 1941, para 32/cem mil, em 1946.

A introdução de métodos preventivos através do saneamento do meio, especialmente em relação à água e deposição de dejetos, produziu melhora no estado de saúde da população. $\mathrm{Na}$ Região da $\mathrm{Ba}-$ cia Amazônica no Perú, por exemplo, antes do programa de saneamento do meio $99 \%$ das crianças em idade escolar foi considerada portadora de infecção ou infestação parasitária. Após aplicação do programa, 4 anos mais tarde, esta taxa baixou para $58 \%$. O custo das medidas preventivas em saúde, embora seja inicialmente alta, pode ser, ràpidamente, compensada por uma redução nos gastos que as doenças teòricamente evitáveis custariam. GIGLIOLI apud UNITED Nations ${ }^{8}$, colculou o custo do tratamento hospitalar por malária, nas Guianas Inglêsas, em 1943, em US\$1.47/hab. $\mathrm{O}$ uso de DDT, com um custo de US\$ $0.63 /$ hab., reduziu o gasto do tratamento hospitalar desta moléstia para US $\$ 0.32 /$ hab. em 1947.
Concluindo, as sulfas, antibióticos, inseticidas, assim como o saneamento do meio foram as armas mais efetivas no combate às enfermidades e a mortalidade. Estes produtos são recentes e foram importados dos países industrializados ao redor de 1940. Em muitos países em via de desenvolvimento a esperança de vida já se situa ao redor dos 60 anos e nos industrializados, em cêrca de 70 anos.

\section{FATORES ECONOMICOS E SOCIAIS QUE} AFETAM A FERTILIDADE

\subsection{Tendência da fertilidade nos países desenvolvidos}

O declínio da natalidade é um dos fenômenos mais discutidos no campo da demografia. Na Europa, o coeficiente de natalidade, para o período compreendido entre 1735-1800, variou de 31-41 nascimentos vivos por mil habitantes. Com flutuações muito pequenas, a natalidade foi mantida nestes níveis até o início de seu declínio que se verificou no último período do séc. 19. Entre os anos de 1841-1845 e 1876-1880 houve uma variação pequena da natalidade $(30-32 / \mathrm{mil}$ hab.) para um período relativamente grande. Nesta época, a França tinha uma natalidade de $25,8 / \mathrm{mil}$ e a Alemanha de $39 /$ mil habitantes ${ }^{9}$.

Uma vez iniciada a queda da natalidade ela continuou, quase que ininterruptamente, em quase tôda a Europa, até 1933-1935, quando o valor mínimo foi atingido. Esta tendência não foi pràticamente alterada pela primeira guerra mundial, com exceção da França, Irlanda e Bélgica em que a natalidade, entre 1921-1930, foi maior do que de 1911-1920.

A natalidade nos Estados Unidos, assim como na França, declinou depois do ano de 1800 . O coeficiente de natalidade de 55/mil, em 1800, foi maior que nos países europeus. Em 1933, êste coe-

(1) Egito, Guiana Britânica, Chile, Costa Rica, E1 Salvador, Jamaica, México, Porto Rico, Ceilāo. 
YUNES, J. - A dínámica populacional dos paises desenvolvidos e subdesenvolvidos. Rev. Sañde públ., S. Paulo, 5:129-50, 1971.

ficiente atingiu o valor de $18 / \mathrm{mil}$ e em $1970,17,6 / \mathrm{mil}$.

A queda da natalidade na Europa variou de acôrdo com a região considerada. Para a natalidade cair de $30 /$ mil para $20 /$ mil decorreram mais de 70 anos para a França, 40 para a Suécia e Suíça e 30 para a Inglaterra e Dinamarca.

O Japão é o único país que não é habitado por pessoas predominantemente descendentes de europeus e que experimentou um declínio da natalidade similar aos Estados Unidos e países europeus. A natalidade no Japão de $35 / \mathrm{mil}$ (1921-5) declinou para 27 (1938) e 19 (1970).

\subsubsection{Fatôres econômicos e sociais}

Vários estudos mostram que os ricos são "menos férteis" que os pobres.

Os opositores de Malthus (na época de sua controvertida declaração, no fim do séc. 18), afirmaram que um aumento da prosperidade econômica seria sempre seguida por um declínio da fertilidade.

$\mathrm{Na}$ França, a explicação da redução da fertilidade para a classe alta foi atribuída ao amor à luxuria, avanço na escala social e desejo de evitar a subdivisão de propriedades para herdeiros.

Vários autores citam diversos fatôres da vida moderna que podem contribuir para a redução da capacidade reprodutiva, tais como: aumento do alcoolismo e das doenças venéreas, maior participação da mulher na fôrça de trabalho, decréscimo das relaçóes sexuais devido ao maior "stress" emocional na vida urbana moderna. Alguns dêstes fatôres têm sido sugeridos como contribuintes e não como agente causal direto no declínio da fertilidade. Não há prova também de que a freqüência do alcoolismo e de doenças venéreas tenha aumentado durante $o$ período em que a natalidade decresceu.

Há concordância quase universal de que o declínio no tamanho da família tem sido devido a prática da limitação da natalidade. A queda da natalidade ocorreu bem antes do desenvolvimento moderno das técnicas contraceptivas. Inves- tigações em diversos países sugerem que o método mais largamente utilizado tem sido a interrupção do coito, técnica conhecida por muitos séculos.

$\mathrm{Na}$ maioria dos países, a prática do abôrto tem sido menos importante que o uso de contraceptivos na redução do tamanho da família, embora haja algumas evidências de que a prática do abôrto está aumentando em alguns países. Em um número reduzido de países, a prática do abôrto tem sido permitida legalmente por motivos médicos, engênicos, criminais ou sócio-econômicos.

\section{a) Mudança de atitude em relação no tamanho da familia}

Os autores mais recentes acreditam que o declínio da fertilidade é devido a um complexo de causas interrelacionadas, atuando uma sôbre a outra, trazendo como conseqüência a sua queda. Alguns tentam explicar que a idéia de limitar o número de filhos e espaçar os nascimentos tem sido adotada, generalizadamente em países industrializados, em troca da tradicional idéia de ter o número de filhos que a "natureza" forneceu.

Tem sido atribuídas diferenças de atitudes em relação ao declínio da mortalidade infantil. Se as pessoas planejam um número definido de filhos, a redução da mortalidade infantil causará, certamente, a redução do número de nascimentos.

Entre as principais razões dadas para não ter filhos ou muitos filhos, as mães, em geral, apontam o mêdo ao desemprêgo, razões econômicas e acomodações habitacionais.

A origem da atitude da limitação do tamanho da família foi aceito, primeiramente, pela classe alta depois pelos demais segmentos da sociedade. Por. exemplo, a queda da fertilidade mais rápida em cidades pode ser devida ao íntimo contato das classes sociais mais baixas com as classes que primeiro praticaram a limitação do tamanho da família. 
YUNES, J. - A dinamica populacional dos paises desenvolvidos e subdesenvolvidos. Rev. Saride puibl., S. Paulo, 5:129-50, 1971.

Eventos históricos, tais como a Revolução Francesa, Crises Econômicas, Depressão na Inglaterra em 1875, influência da opinião pública, etc., são considerados como tendo sido favoráveis à atitude de limitação do tamanho da família.

A libertação do tradicionalismo, com conseqüente mudança dos valores e padrōes de comportamento, é também citado como fator contribuinte para o dechinio da fertilidade.

\section{b) Urbanização}

O declínio da fertilidade tem sido precedido e acompanhado, em todos os paises, pela urbanização. comum os autores afirmarem que a população urbana é "menos" fértil que a rural.

A relação entre o processo de urbanização e queda da fertilidade é complexa. A maioria dos autores acredita que as grandes cidades modernas favorecem o desenvolvimento de atitudes motivando a limitação do tamanho da família. Alguns autores chegaram a afirmar que o meio urbano é uma condição essencial para o desenvolvimento desta atitude ("mentalidade urbana").

Entre os principais fatôres que favoreceram a limitação da natalidade em cidades citam-se: Vida famliar menos coesa; crianças não são consideradas uma vantagem econômica; aspiração de melhor status social e econômico; prevalece maior racionalização e libertação de tradições.

E importante chamar a atenção que, em geral, a diferença entre fertilidade urbana e rural existiu em muitos países antes do início da queda da natalidade (séc. 17 e 18 na Europa e América do Norte). No séc. 19, a fertilidade urbana e rural começou a decrescer em alguns países, sendo que a queda da urbana foi mais rápida. Em geral, tem sido encontrado que quanto maior é a cidade mais baixa é a fertilidade ${ }^{9}$.

\section{c) Mobilidade social}

0 desejo de melhorar a posição na escala social tem sido apontado como um motivo importante para a limitação do tamanho da família.

0 efeito da mobilidade social sôbre a fertilidade parece ser atribuída, em geral, ao fato de que criar uma criança significa gastar dinheiro, tempo e esfôrço, os quais poderiam ser utilizados para subir na escala social. Desta maneira, a mobilidade social é mais factível com um número pequeno de crianças do que com um grande.

\section{d) Status da mulher e organização fa- miliar}

A mudança no status e no papel da mulher tem sido uma das razóes para a diminuição do tamanho familiar.

Fatôres freqüentemente mencionados como contribuintes para a mudança de atitude da mulher são:

- Aumento do nível educacional.

- Igualdade para a mulher em muitas esferas da vida pública.

- Igualdade do papel da mulher no casamento.

- Oportunidade para um maior desenvolvimento $\mathrm{da}$ personalidade $\mathrm{e}$ independência.

- Maior grau de participação da mulher na fôrça do trabalho. Tal fator tem sido freqüentemente relacionado ao grau de urbanização e industrializaçấo. Diversos censos têm mostrado que o número de filhos de mulheres casadas que trabalham é menor que o das que não trabalham.

- Com a industrialização, as atividades econômicas exigem que a mulher fique fora do lar, competindo com o seu trabalho caseiro e com as atividades de cuidar de crianças. Hoje é largamente aceito que nas sociedades industrializadas as mulheres evitam criar crianças ou restringe seu número a fim de manter o emprêgo fora de casa. 
YUNES, J. - A dinamica populacional dos paises desenvolvidos e subdesenvolvidos. Rev. Saúde públ., S. Paulo, 5:129-50, 1971.

- A mudança no padrão da organizaçáo familiar tem sido responsável pelo declínio da natalidade e do tamanho familiar. Um importante fator, responsável pela queda da fertilidade, foi a transição de família tradicionalmente estável para instável.

Autores mais recentes enfatizam que a família não é mais a unidade econômicamente produtiva e que a sua função na criação da criança tem sido favorecer principalmente um maior nível educacional e vida associativa. Conseqüentemente, um aumento da concentração emocional sôbre a criança tem paradoxalmente sido a razáo para a limitação do tamanho da família.

\section{e) Nivel de vida e custo na criação de crianças}

As famílias são menores nos países onde os níveis de vida são mais altos. Dentro do periodo da queda da natalidade os ricos têm, geralmente, menos crianças do que os pobres, o que tem sido sugerido que um aumento na riqueza diminui a fertilidade. Tem sido notado que, acompanhando a queda da natalidade entre os ricos, o declínio tem sido apresentado também nos grupos pobres. Particularmente isto tem sido verdadeiro para as grandes cidades.

0 aumento do ingresso econômico torna possível uma maior seleção das atividades no lazer e no tempo. 0 cuidado à criança pode ser considerado uma interferência na satisfação de outros desejos.

O custo econômico na criação de crianças aumentou consideràvelmente durante o período de declínio da natalidade. $O$ emprêgo de crianças em agricultura e indústrias tem sido cada vez mais restringido. A influência da legislação, proibindo o emprêgo de crianças, obrigatoriedade no atendimento escolar e a extensão do período educacional, tem sido, muitas vêzes, responsabilizado pela dimi- nuição do número ideal de filhos. Como resultado, as crianças têm que ser mantidas por seus pais por um período mais longo. 0 melhor padrão da assistência médica, o maior cuidado dedicado à criança e o aumento do padrão geral de vida, aumentaram substancialmente o custo da criação da criança.

\section{f) Ocupação}

Censos em diversos países fornecem dados do número de filhos de mulheres casadas, classificadas pela atividade econômica de seus esposos. Geralmente, quanto mais diferenciada é a ocupação e melhor a qualificação da mão de obra, menor é a fertilidade.

\section{g) Educação}

Estudos sôbre fertilidade, relacionados ao nível educacional do marido e da mulher, têm geralmente mostrado que quanto maior escolaridade, menor é o número de filhos. Em geral, as mulheres de nivel colegial e universitário têm baixa fertilidade, casam menos do que a população em geral e o fazem em idade mais avançada (principalmente as universitárias).

\section{h) Religiäo e padröes de casamento}

Tem sido, muitas vêzes, admitido que o declínio do interêsse religioso tem contribuido para a limitação do tamanho da família. $E$ inferido que o interêsse religioso tem diminuído, como valor tradicional, à medida que o pensamento racionalista tem lugar.

Em geral, quando há praticidade da religiảo, a prática do uso de contraceptivos é menor e a fertilidade é maior, comparativamente com os não praticantes.

Grandes diferenças têm sido observadas na fertilidade diferencial dos diversos grupos religiosos. Numerosos estudos sôbre Católicos, Protestantes e Judeus, em vários países Europeus e nos EUA, Ca- 
YUNES, J. - A dinamica populacional dos paises desenvolvidos e subdesenvolvidos. Rev. Saride públ., S. Paulo, 5:129-50, 1971.

nadá e Austrália, têm demonstrado que a fertilidade é geralmente maior entre os católicos e menor entre os judeus. Contudo, mesmo a fertilidade entre católicos tem declinado enormemente em todos os países europeus e nos EUA. As diferenças de fertilidade entre os grupos religiosos, tomados como um todo, parecem estar intimamente relacionadas às diferenças econômicas e ocupacionais discutidas anteriormente. Entre membros da mesma ocupação e nível econômico, os católicos, em média, são mais férteis que os protestantes. No entretanto, as diferenças de fertilidade entre pessoas da mesma religião mas de diferentes graus de ocupação, ingresso per capita, nível educacional, etc., são muito grandes.

A proporção da dissolução de casamentos ou da viuvez tem sido considerada como menos importante na mudança de fertilidade a longo prazo.

\section{i) Outros fatôres}

A queda da mortalidade entre crianças e jovens tem sido um dos fatôres responsáveis para o declínio do tamanho da família. A proporção de crianças que sobrevivem tem aumentado, o que indicará uma carga maior para o seu sustento.

Deficit habitacional, pobreza, insegurança econômica, desemprêgo e mêdo de guerra têm sido outras causas que sugerem a explicação do declínio da natalidade.

\subsection{Tendência da fertilidade nos paises subdesenvolvidos}

Para êstes paises, a estatistica de natalidade, quando existe, é de qualidade bastante precária. As populações da África, Ásia, América Latina e da Oceania (fazem exceção os europeus ou seus descendentes) apresentam alta fertilidade. Possivelmente, na maioria dos casos, a natalidade foi mais alta do que na Europa Ocidental antes do início da grande queda que começou nos meados do séc. 19.
Para a América Latina a natalidade nos anos de 1932-1938, variou de 30 nascimentos vivos por mil habitantes (Venezuela) para $47,7 / \mathrm{mil}$ (Guatemala). Para o período de 1946-1950, êste coeficiente variou de $33,1 / \mathrm{mil}$ (Chile) até $48,0 / \mathrm{mil}$ (Brasil) e 50,5/mil (Guatemala). Para 1970, êste coeficiente variou de 22/mil (Argentina) para 49/mil (Honras) ${ }^{5}$. Este aumento de fertilidade que se verificou para anos mais recentes, tem tido diversas interpretaçōes, entre elas, a melhoria do registro de dados. Para os países da África, Ásia e Oceania a natalidade alcançou, para o período de 1946-1950, o valor de 43,0/mil no Egito, $43,4 / \mathrm{mil}$ em Singapura e $46,0 / \mathrm{mil} \mathrm{em}$ Nova Zelândia e para 1970 a natalidade oscilou de 22,6 (Nova Zelândia) para 50 (Nigeria).

Embora os dados para países com alta fertilidade sejam fragmentados, a natalidade parece estar geralmente em tôrno ou acima de $40 / \mathrm{mil}$.

\subsubsection{Fatôres que afetam a alta fertili- dade}

\subsubsection{Padrôes de casamento}

Onde os dados existem, êles geralmente mostram que, em países de alta fertilidade, o casamento de mulheres ocorre em idades mais precoces. No Ceilão (1946) $71 \%$ das mulheres no grupo etário de 20-24 anos foram ou estavam casadas; na India (1931) esta proporção foi de 95\%. No Egito (1946) 88\%; Trinidade (1946) 62\%; Peru (1940) 52\%; Brasil (1940) 46\%. Esta proporção menor de casamentos para a América Latina em relação aos da Ásia e África foi atribuída a um grande número de casamento consensual.

\subsubsection{Fatôres sociais e econômicos}

- Menor prática da limitação da natalidade. 
YUNES, J. - A dinamica populacional dos paises desenvolvidos e subdesenvolvidos. Rev. Saúde públ., S. Paulo, 5:129-50, 1971.

- Casamento em idade precoce: alguns autores acreditam que a reprodução, nestes países, está perto do limite da capacidade biológica.

- Baixo nível educacional.

- Grande dependência das atividades agrícolas.

- Baixo nivel econômico.

- Atitude fatalista em relação ao nascimento e morte.

— Injunções religiosas.

- Forma de organização familiar.

- Alta mortalidade resultando em pequeno número de crianças com sobrevida.

\subsubsection{Fertilidade diferencial}

As diferenças de fertilidade urbano-rural, por tipo de ocupação, religião e educação apresentam, em linhas gerais, o mesmo grau de interpretação da análise feita para os países que apresentam fertilidade baixa.

\section{POLfTICA POPULACIONAL}

Como foi descrito na análise do crescimento populacional, os continentes que compõem o assim chamado terceiro mundo são os que apresentarão o maior contingente populacional quando comparado com os países que formam o mundo desenvolvido.

Esta situação preocupa, cada vez mais, os países, principalmente os desenvolvidos. Recentemente, o Presidente do Banco Mundial (Robert Mac Namara ${ }^{(1)}$ ) declarou que um bilhão de nascimentos devem ser "evitados" no Terceiro Mundo, nos próximos 30 anos, para conter a explosão demográfica. De 68 países subdesenvolvidos, 20 têm política oficial de contrôle populacional e programas de planejamento familiar, 20 não têm política definida mas desenvolvem programas de planejamento familiar e 28 não têm nem política oficial e nem programas, conforme Tabela 5 .

De acôrdo com a posição governamental, $66 \%$ da população de todos os países subdesenvolvidos está sob uma política

T A B E L A 4

Estimativas da natalidađe e da taxa bruta de reprodução para as diversas regioes do mundo em anos próximos a 1960

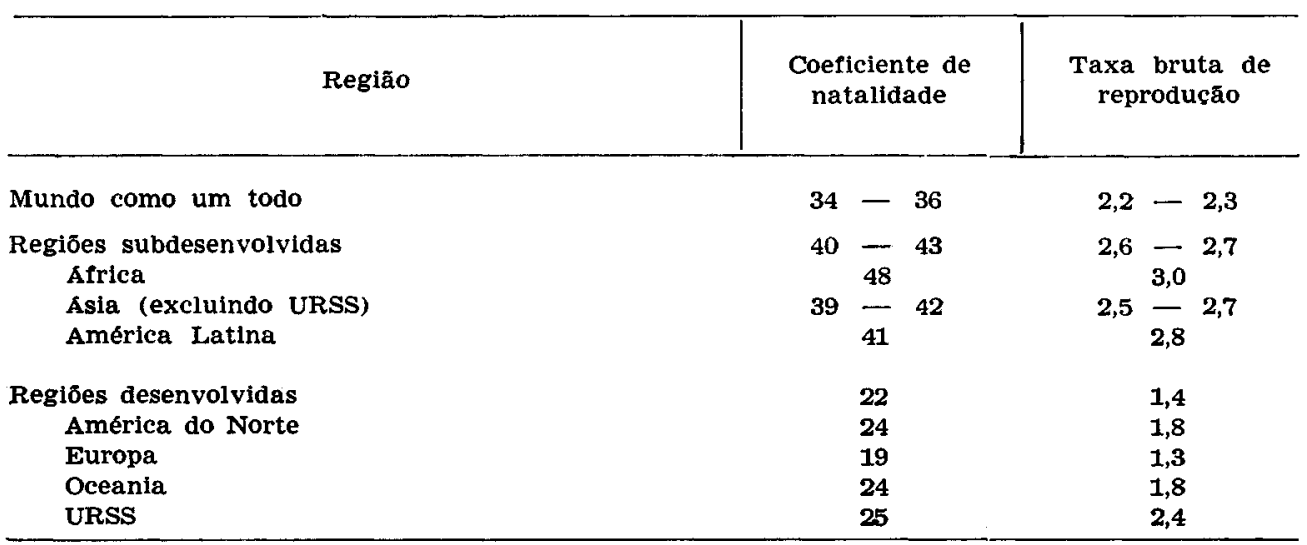

Fonte: School of Public Health. University of Michigan (notas de aula).

(1) A Folha de São Paulo, 22 set. 1970. p. 19. 
YUNES, J. - A dinámica populacional dos paises desenvolvidos e subdesenvolvidos. Rev. Saude públ., S. Paulo, 5:129-50, 1971.

T A BE L A 5

Posição governamental em programas de planejamento famillar e sua politica para 68 palses subdesenvolvidos

\begin{tabular}{|c|c|c|c|}
\hline \multirow[b]{2}{*}{ Regiāo } & \multicolumn{3}{|c|}{ Posiço governamental } \\
\hline & $\begin{array}{l}\text { Politica e Programa } \\
\text { de Planejamento } \\
\text { Familiar (P.F.) }\end{array}$ & $\begin{array}{l}\text { Polltica não definida } \\
\text { mas com programas } \\
\text { de P.F. }\end{array}$ & $\begin{array}{c}\text { Sem politica e } \\
\text { sem programa } \\
\text { de P.F. }\end{array}$ \\
\hline \multicolumn{4}{|l|}{ Africa } \\
\hline 20 paises & 6 & 4 & 10 \\
\hline \multicolumn{4}{|l|}{ América Latina } \\
\hline 18 países & $2 \underset{\text { Trinidade) }}{\text { (Jamaica e }}$ & 13 & 3 \\
\hline Asia & & & \\
\hline 30 paises & 12 & 3 & 15 \\
\hline Total & 20 & 20 & 28 \\
\hline
\end{tabular}

Fonte: Reports on Population: Family Planning (Population Council) Dec. 1969.

antinatalista oficial. 0 continente que mais contribui com esta política é o asiático, pois $98 \%$ da população da Ásia Oriental e $81 \%$ da Ocidental estão sob uma política oficial de contrôle populacional. A distribuição populacional por região sob os diferentes tipos de políticas populacionais a que estão submetidas, é apresentada na Tabela 6.
Nos países subdesenvolvidos, os contraceptivos mais utilizados pelos programas de planejamento familiar são, em ordem decrescente: Dispositivo Intra Uterino (DIU), Esterilização e Pílulas. Sòmente a fndia, durante um período de 4 anos (1964-68), esterilizou 5.200.000 habitantes, com uma idade média de 32,2 anos; o Paquistão 597.000, a Tailândia

TABELA 6

Distribuicão da populaçao nas principais regiōes do mundo subdesenvolvido de acôrdo com a posição governamental em planejamento familiar e politica populacional

\begin{tabular}{|c|c|c|c|c|c|c|}
\hline Posição & governamental & $\begin{array}{c}\text { Todos os } \\
\text { paises sub- } \\
\text { desenvolvi- } \\
\text { dos }\end{array}$ & Africa & $\begin{array}{c}\text { América } \\
\text { Latina }\end{array}$ & $\begin{array}{c}\text { Asia } \\
\text { Oriental }\end{array}$ & $\begin{array}{c}\text { Asla } \\
\text { Ocidental }\end{array}$ \\
\hline
\end{tabular}

População em milhơes e distribuiçăo percentua]

\begin{tabular}{|c|c|c|c|c|c|}
\hline Todas as posiçoes & $2478(100 \%)$ & $344(100 \%)$ & $249(100 \%)$ & $804(100 \%)$ & $1081(100 \%)$ \\
\hline $\begin{array}{l}\text { Politica antinatallsta ofi- } \\
\text { cial e programa de P.F. }\end{array}$ & $1630(66)$ & $73(21)$ & $3(1)$ & 785 (98) & 881 (81) \\
\hline $\begin{array}{l}\text { Programas de P.F. mas } \\
\text { sem presenca de política } \\
\text { oficial }\end{array}$ & $334(13)$ & $73(21)$ & $73(29)$ & $4(0)$ & $72(7)$ \\
\hline
\end{tabular}

Poucas atividades em P.F.

e sem politica antinatalista ofictal

$514(21) \quad 198(58) \quad 173(70) \quad 15(2) \quad 128$ (12)

Fonte: Reports on Population: Family Planning (Population Council) Dec. 1969. p. 20. 
YUNES, J. - A dinâmica populacional dos paises desenvolvidos e subdesenvolvidos. Rev. Saúde públ., S. Paulo, 5:129-50, 1971.

TABELA 7

Número acumulado de receptores por tipo de contraceptivo (por 1.000) em alguns paises

\begin{tabular}{|c|c|c|c|c|c|c|}
\hline Pais & DIU & Pilula & Esterllização & & Ano & \\
\hline Ceillão & 48,1 & 26,9 & 11,8 & 1966 & - & 1968 \\
\hline Chile & 259 & - & 0 & 64 & - & 68 \\
\hline Colómbia & 74 & 16,6 & - & 64 & - & 68 \\
\hline República Dominlcana & 1,7 & 1,6 & - & 64 & - & 68 \\
\hline Hong-Kong & 69 & 17 & $\mathbf{2}$ & 64 & - & 68 \\
\hline India & 2632 & 0 & 5200 & 64 & - & 68 \\
\hline Indonésia & - & - & 0 & 64 & - & 68 \\
\hline Iran & 25 & 50 & 0 & 67 & - & 68 \\
\hline Kenya & 15 & - & - & 66 & - & 68 \\
\hline Coréia do Sul & 1323 & 76 & 118 & 64 & - & 68 \\
\hline Malasia & 1,9 & 88,0 & $\mathbf{3 , 3}$ & 67 & - & 68 \\
\hline Marrocos & 19 & 2 & 0 & 64 & - & 68 \\
\hline Nepal & 5,0 & 0,2 & 2,0 & 66 & - & 68 \\
\hline Paquistão & 2071 & 0 & 597 & 64 & - & 69 \\
\hline Singapura & 7,8 & 55,6 & - & 65 & - & 68 \\
\hline Formosa & 505 & 63 & 1,2 & 64 & - & 68 \\
\hline Tallândia & 121 & 18 & 123 & 64 & 一 & 68 \\
\hline Tunisia & 48 & 3,6 & 4,0 & 64 & 一 & 68 \\
\hline Turquia & 136 & -7 & - & 64 & - & 68 \\
\hline RAU & 88 & - & - & & 68 & \\
\hline
\end{tabular}

Fonte: Reports on Population: Family Planning (Population Council) Dec. 1969.

123.000 pessoas. A seguir, apresentamos, por país, o número acumulado de receptores por tipo de contraceptivo utilizado em alguns países.

Pode-se afirmar, no entretanto, que a taxa de natalidade, na maioria dêstes países, não foi reduzida. Não estaria a queda da fertilidade relacionada ao desenvolvimento social e econômico, como ocorreu nos países desenvolvidos com a revolução industrial? o desenvolvimento demográfico acelerado a verdadeira causa do subdesenvolvimento? Qual a natureza do problema? Trata-se de problema médico? Será a explosão demográfica uma doença a merecer tratamento médico urgente ou será uma crise social a exigir medidas de âmbito e natureza diferentes?

O problema demográfico é diferente a cada país, porém, as generalizações de abordá-lo não correspondem à realidade brasileira e nem de muitas outras naçōes. No que se refere ao importante e controvertido problema da relação entre tamanho da população, índice de crescimento populacional e desenvolvimento econômico deve-se, em cada caso particular, estudar as condiçōes concretas de relação entre recursos naturais e população e a capacidade de assimilação de mãode-obra pelo processo de desenvolvimento de cada sistema econômico. As relações entre desenvolvimento econômico e população, bem como as motivações econômicas, sociais e culturais tendentes a condicionar índices diferenciais da fertilidade, são de natureza complexa merecendo, certamente, estudos complementares.

0 que não se pode aceitar de modo pacífico é o ponto de partida de muitos autores neo-malthusianos que reduzem o desenvolvimento econômico ao crescimento de renda per capita, atribuindo a divisão do Produto Nacional Bruto, pelos novos indivíduos que nascem, como um fator de atraso social e estagnação econômica. 
YUNES, J. - A dinamica populacional dos paises desenvolvidos e subdesenvolvidos. Rev. Saide pribl., S. Paulo, s:129-50, 1971.

"O tamanho, a estrutura e o crescimento da população têm um efeito duplo sôbre o funcionamento da economia: êles são os principais determinantes da oferta de fôrça de trabalho e, ao mesmo tempo, influem fortemente no consumo. Os efeitos da dinâmica populacional são, portanto, sentidas simultâneamente tanto do lado da oferta como do lado da procura de bens e serviços" 6 .

"E fora de dúvida que população e nível de renda são os principais determinantes do tamanho do mercado; do ponto de vista das economias da escola, a população é o fator mais significativo. Embora a proposição de que o crescimento demográfico amplia o mercado não possa ser generalizada irrestritamente, continua, não obstante, a ser verdade que, para, pràticamente, qualquer país capaz de desenvolver sua economia, uma população maior significa um mercado maior e, conseqüentemente, uma maior latitude de industrialização. Ao contrário da integração econômica, o crescimento populacional não depende de acôrdos com outros países e representa, por isso, uma "solução" de mais fácil aplicação para um problema vital. Daí se concluir que, exceto no caso de alguns países com população bem grande, a expansão populacional é um fator positivo, a longo prazo, para o desenvolvimento. Portanto, a avaliação do efeito do crescimento populacional para o desenvolvimento deve ser feito à luz das condições específicas em que cada país se encontra" 6 .

Assim sendo, podemos considerar, de início, que a demografia desempenha em saúde pública as seguintes funçōes primordiais:

a) Em planejamento de saúde. E através das combinações das variações demográficas, tais como: natalidade, mortalidade e tamanho da população segundo a composição por sexo e idade, que se permite calcular os coeficientes componentes dos indicadores globais e específi$\cos$ que medem o estado de saúde da po- pulação, etapa importante para o planejamento. Os estudos de mortalidade e morbidade representam, também, uma contribuição relevante para o planejamento de saúde. Para se determinar o padrão quantitativo ou necessidades dos recursos de saúde, torna-se necessário o dado demográfico população, a fim de se analisar a proporção de habitantes por tipo de equipamento existente, tais como, população teòricamente coberta por unidade sanitária, número de leitos por mil habitantes, população atingida pela rêde de abastecimento de água e esgôto, número de habitantes por médico e pessoal paramédico, assim como muitas outras correlações.

Tendo em vista o progresso nas análises e projeções demográficas, a demografia deverá desenvolver um papel mais importante no planejamento dos serviços de saúde.

Exige o planejamento moderno de saúde características mais completas e exatas da população. Torna-se fundamental, neste planejamento, levar-se em conta as variáveis demográficas e a composição social da população para se construir modêlos mais realistas, possibilitando programar efetivamente as necessidades de saúde, tais como: unidades sanitárias, leitos hospitalares, pessoal médico e auxiliar de saúde, etc. A análise da distribuição da população e de sua migração torna-se elemento fundamental para caracterizar o tipo e a organização da assistência médico sanitária. 0 conhecimento da natalidade, fertilidade e nupcialidade permite avaliar a necessidade de leitos maternidades $e$ infantis, assim como de serviços pré-natais.

Estudos relativos à estrutura e à dinâmica populacional, assim como a sua tendência, são bastante necessários para contribuir na formulação de uma política de saúde.

O desenvolvimento futuro dos meios técnicos e da estatística enriquecerão ainda mais a informação acêrca dos progres- 
YUNES, J. - A dinamica populacional dos paises desenvolvidos e subdesenvolvidos. Rev. Saride pribl., s. Paulo, s:129-50, 1971.

sos demográficos e irá, portanto, contribuir para o aperfeiçoamento da planificação da assistência médica.

b) 0 correlacionamento entre migração e saúde constitui também uma importante aplicação da demografia em saúde pública, embora esta dimensão da demografia em saúde tenha sido ainda precária, necessitando maiores estudos e investigações.

c) Estudos sôbre a erradicação das doenças de massa e o seu efeito sôbre a redução da mortalidade, trazendo como conseqüência, o crescimento populacional, merece, também, atenção especial da saúde pública a fim de fornecer subsídios para os programas e planejamento de desenvolvimento social e econômico.

d) Nos programas de higiene materno infantil, o estudo das correlaçōes entre variáveis demográficas e saúde fornecem importantes informaçóes para integrar o planejamento familiar aos programas de saúde. Para isto, tornam-se importantes investigaçōes que mostrem como se comporta, por exemplo, a natimortalidade e mortalidade infantil de acôrdo com a paridade, idade materna e espaçamento entre os nascimentos; que benefícios traz o aumento do espaçamento na saúde materna; qual a relação encontrada entre idade materna e incidência de prematuridade e malformaçōes congênitas; que correlações existem entre paridade, perdas fetais e prematuridade; paridade e câncer genital; qual o efeito da lactação na fertilidade; e o do casamento consanguíneo nas malformações congênitas.

A par do tamanho da família deve ser de livre escolha do casal, as condiçōes médicas e biológicas constituem um importante fator para o aconselhamento do planejamento familiar. Esta prática, acompanhada de um programa de educação sexual, representa uma importante medida de higiene materno infantil e, portanto, de saúde pública. A esterili- dade deve ser também uma importante preocupação nas pesquisas biológicas e médicas. Portanto, constitui o planejamento familiar parte de um serviço organizado de saúde, sem impedir, no entretanto, sua função preventiva e curativa mas sim integrando-a. Esta posição foi definida também pela 19. Assembléia da OMS (1966). Sendo assim, não é preciso justificativas econômicas, sociais e demográficas, para incluir o planejamento familiar como um dos muitos programas de assistência materno infantil. Têm sido os médicos e outros profissionais de saúde os que mais se utilizam dêste argumento, apesar de faltar-lhes, em geral, conhecimentos básicos de economia, ciências sociais e demografia.

Tem sido também a incidência do abôrto induzido superestimada para justificar a implantação do Planejamento Familiar. Com exceção do trabalho de HutchinSON $^{3}$ (1964) e MrLaNESI ${ }^{4}$ (1968), (a incidência de abôrto provocado encontrado foi de $9,2 \%$ e $10,71 \%$ respectivamente), os dados que existem no Brasil referem-se a dados hospitalares, o que impede o conhecimento da magnitude real do problema e das variáveis nêle implicadas, uma vez que tais dados são, por natureza, selecionados, não refletindo o que se passa na população, não permitindo, portanto, a sua extrapolação para tôda a população feminina, como tem sido feito por alguns autores. De acôrdo com a investigação realizada sôbre o Ensino do Contrôle da Fertilidade nas Escolas Médicas Brasileiras (Yunes ${ }^{10}, 1970$ ), o abôrto provocado não se apresentou como indicaçáo prioritária para o planejamento familiar, tendo ocupado o quarto lugar, precedido das indicações por motivos de doenças e problemas psiquiátricos; retardamento mental; limitação do tamanho da família e problema sócio-econômico; defeito genético e aumento de espaçamento.

e) Os países subdesenvolvidos indicam, em geral, como prioritários os problemas ligados ao saneamento básico, nu- 
YUNES, J. - A dinâmica populacional dos paises desenvolvidos e subdesenvolvidos. Rev. Saúde públ., S. Paulo, 5:129-50, 1971.

trição, educação, assistência médica hospitalar, combate às moléstias transmissíveis, problemas diretamente ligados à estrutura econômica e social da nação e que só podem ser resolvidos com as transformaçốes sociais necessárias ao processo de desenvolvimento.

f) Não cabe ao setor saủde, isoladamente, definir uma política de população, cabendo esta tarefa à esfera federal, de acôrdo com a política de desenvolvimento social e econômico definida pelo govêrno.

Em resumo, é o Brasil um país de extensa área geográfica, com um grande contingente populacional e imensos recursos naturais. Não cremos que um país com estas características necessite de uma política de contrôle populacional para resolver o problema de seu subdesenvolvimento. Mas sim, de reformas estruturais e políticas que o conduzam a um desenvolvimento social e econômico integrado e harmônico. Isto não impede, no entretanto, que se desenvolva o planejamento familiar, a nível de indivíduos e famílias, através dos serviços de assistência materno-infantil, proporcionando, portanto, uma assistência médica global e integrada. É competência exclusiva de cada nação soberana decidir sôbre êstes assuntos e não devem ser impostos programas de planejamento familiar por nenhum organismo internacional em sua programação regional ou subregional.

\section{5. $C O N C L U S O E S$}

- $O$ crescimento populacional acelerado ("explosão demográfica") é consequiência e não causa do subdesenvolvimento e como tal não é problema médico.

- Sòmente o ingresso dos países subdesenvolvidos no processo de desenvolvimento econômico e social reduzirá substancialmente a mortalidade e fertilidade. Històricamente pela análise feita por êste estudo, isto ocorreu para os países considerados hoje desenvolvidos.

- A demografia tem aplicações importantes em saúde pública, principalmente em planejamento de saúde.

- O planejamento familiar deve ser parte integrante da assistência materno-infantil, respeitando sempre as prioridades de um programa de saúde.

- Não é preciso justificativas demográficas, econômicas e sociais para se incluir o planejamento familiar em programas de saúde, uma vez que a causa de pobreza e de subdesenvolvimento não reside no tamanho da família.

- A política populacional deve ser definida pelo govêrno federal de acôrdo com a política de desenvolvimento social e econômico do país.

YUNES, J. - [Population dynamics on the developed and underdeveloped countries]. Rev. Sauide pribl., S. Paulo, 5:129-50, 1971.

Summary - The main factors that contributed to the population dynamic in developed and underdeveloped countries and the policies of these countries used, even the aplication of demography in Public Health, are analysed. The greater population growth in under developed countries is observed. Thus, by the year 2000 , the region called "third world" will present the higger population contingent, for the underdeveloped countries will contribute with $79 \%$ from the total world population. The first demographic transition began in 17th century in Europe with the process of industrial revolution while in underdeveloped countries this occurred in the beginning of 1940 with a deep difference since the decline of mortality rate presented was not followed either by a significative decline of birth rate, or even by the modernization of their economics. Among the main factors that influenced mortality and fertility factors are the influence of economic and social development, and also the progress in medical 
YUNES, J. - A dinámica populaclonal dos paises desenvolvidos e subdesenvolvidos. Rev. Saúde puibl., S. Paulo, 5:129-50, 1971.

and public health fields. $66 \%$ of underdeveloped countries population is under birth rate control and in a decrescent order the most used contraceptive has been the intrauterine device (IUD), sterilization and pills. India, in four years (1964-68), sterilized 5,200.000 inhabitants with an average age of 32 years old. The health planning, migration, epidemiology and maternal and child health are mentioned among the main applications of demography on Public Health.

UNITERMS - Demography control *; Population growth *; Public Health*.

\section{REFERENCIAS BIBLIOGRAFICAS}

1. ASOCIACION COLOMBIANA DE FACULTADES DE MEDICINA - Introducción a la dinamica de población. Bogotá, Tercer Mundo, s.d. p. 15-9.

2. DORN, H. F. - World population growth. In: HAUSER, P. E., ed. - The population dilemma. Englewood Clifts, N. J., PrenticeHall, 1965. p. 7-28.

3. HUTCHINSON, B. - Induced abortion in Brazilian married women. Amer. Lat., 7 : 21-33, 1964.

4. MILANESI, M. L. - Abôrto provocado: estudo retrospectivo em mulheres năo sol- teiras, de 15 a 49 anos, residentes no Distrito de São Paulo, em 1965. São Paulo, 1968. [Tese - Faculdade de Higiene $e$ Saúde Pública-USP].

5. POPULATION REFERENCE BUREAU. [Quadro demográfico mudial]. Washington, D.C., 1970.

6. SINGER, P. I. - O papel do crescimento populacional no desenvolvimento economico. São Paulo, 1968. [Tese - Faculdade de Higiene e Saúde Pública-USP].

7. TAEUBER, I. B. - Population growth in underdeveloped areas. In: HAUSER, P. M., ed. The population dilemma. Englewood Cliffs, N. J., Prentice-Hall, 1965. p. 29-45.

8. UNITED NATIONS. Department of Social Affairs - Economic and social factors effecting mortality. In: - The determinantes and consequences of populations trends. New York, 1953. p. 47-70.

9. UNITED NATIONS. Department of Social Affairs - Economic and social factors affecting fertility. In: The determinantes and consequences of population trends. New York, 1953. p. 71-97.

10. YUNES, J. - 0 ensino do controle da fertilidade e de problemas populacionais em escolas médicas brasileiras. Rev. Saude príbl., S. Paulo, 4:79-84, 1970. 